\title{
Editorial: Himalayan Climate Interaction
}

\author{
A. P. Dimri ${ }^{1 *}$ and Simon Allen ${ }^{2}$ \\ ${ }^{1}$ School of Environmental Sciences, Jawaharlal Nehru University, New Delhi, India, ${ }^{2}$ Eclim: Research Group on Environment \\ and Climate, Department of Geography, University of Zurich, Zurich, Switzerland
}

Keywords: Himalayas, glacier, river, monsoon, climate change, climate

\section{Editorial on the Research Topic}

\section{Himalayan Climate Interactions}

The Himalayas, water tower of Asia, is an important water source for the downstream habitats for drinking, sanitation, irrigation, hydropower generation, etc. for over 1.35 billion people. The Himalayan glaciers are estimated to provide around $8.6 \times 10^{6} \mathrm{~m}^{3}$ of water annually to the Asias seven major rivers. However, considerable uncertainties remain around the long-term sustainability of this vital resource.

Looking into the past, the Himalayas derived the serenity of monsoon systems, but at times was part of disastrous impacts/events at different scales. Many civilizations lived and prospered around the Himalayan fed rivers. At some points there were also drought periods; the Himalayas has stored all this information too, which led the researchers to investigate these Palaeo information to look into the past.

In the present context, the Himalayas is one of the biodiversity hotspots regions of the world. It has diverse forests, providing ecosystem services for both upland and lowland communities. In addition, it controls weather and climate systems at local-regional-global scale. It controls, drives and determines the associated climate impacts, thus leading to coupled atmosphere-hydrospherecryosphere interactions which at times are elusive due to the paucity of in-situ observations.

Recent climate change associated disasters viz., floods, landslides, avalanches, etc. mainly originate from mountain slopes and/or catchments. They have significant and far-reaching consequences leading to enormous losses across the Himalayas. Climate change potentially influences both the frequency and the magnitude of extremes in the Himalayan region. Issues related to the retreat of glaciers, thawing of frozen slopes, increased heavy rainfall, glacial lakes increasing in number, snow-ice melts, etc. will have disaster risks. In addition, issues related to mountain dependent economic solutions, infrastructural developments, and employments to the mountain communities will be adversely impacted.

A key challenge is to maintain a sustainable status which can behold the aftermath of climate change related disasters leading to impact local and/or national mountain economy. Therefore, this present special volume has been conceived to highlight some of these issues within scientific realms and in brief are presented below.

In order to reconstruct long-term recession rates of the debris covered Milam glacier situated in the Gori Ganga valley, Uttarakhand Himalaya, Mal et al. incorporated historical maps, high resolution Corona and recent satellite data to assess it. Over the past five decades, estimation shows $\sim 1.5 \mathrm{~km}$ of retreat, area loss and detachment of two tributary glaciers from the main trunk. Thus, 
leading to glacier thinning and melting. Based on reconstruction profile from a fluvio-lacustrine section, climatic change event during the late Pleistocene to the early Holocene is presented by Sanwal et al.. They have shown two major climatic events: Last Glacial Maximum (LGM) and Older Dryas (OD). Warm and moist conditions are identified at around 25,000 years BP, possibly coinciding with the intensification of the Indian Summer Monsoon. Based on this information, the onset of a cold and arid phase is evident in the gradual shift in vegetation pattern from C3 to C4 plants. The profile also shows that the LGM phase gradually transformed into a warm and moist climate. Further, Sharma and Phartiyal highlighted improved methods and data providing new understanding and signature regarding moisture sources over the trans-Himalayan region of northwest India. It is important to mention that these regions host thousands of glaciers ensuring perennial freshwater supply to the downstream habitat. These enhanced tools will enable scientists to provide comprehensive details on interactions of Himalayan orography with the moisture-carrying winds during Indian summer and winter monsoon both.

Discrepancies in chronology between and within different dating techniques, pose a serious challenge and therefore required to be addressed. Based on recent water isotopic studies, the authors inferred that Upper Indus River Basin receives moisture from the Indian summer monsoon as well in addition of the Indian winter monsoon from the Mediterranean Sea. The direct and non-delayed response of glaciers in terms of their mass balance is a key signal of climate change. Singh et al. present a review on glacier mass balance changes under the changing climate in the Indian Himalayan Region (IHR). A status of continuous negative mass balance is reported, with a few exceptions for a year or two, reflecting the overall negative mass balance with increasing trend in recent decades. These responses are in coherence with the corresponding increase/decrease in temperature and precipitation patterns. These changes will have a direct impact on future water need and/or water availability; thus, leading to impacts on the downstream communities and their livelihoods. A temporal inventory of glacial and high-altitude mountain lakes in the Sikkim region of the Eastern Himalaya is presented by Shukla et al.. Based on multi-temporal lake changes, their nature and occurrence pattern is analyzed. An existence of 463 glacial and high-altitude lakes $\left(>0.003 \mathrm{~km}^{2}\right)$ in the year 2000 are grouped into four different geomorphic classes. The number of lakes increased by 9\% between 1975 and 2017, accompanied by a rapid areal expansion. The results show that regional climate change is accelerating the thawing of the cryosphere, with glacier melting likely to continue into the future. Thus, formation of new lakes and expansion of existing lakes will lead to an increase in the potential for glacial lake outburst floods. Thereby, persistent attention should be paid to the influences of climatic change in the region. Thayyen and Dimri demonstrate the critical interplay of moisture and temperature leading to precipitation due to orographic mechanisms in the mountainous Himalayan region. The main finding of the study is defining and determining Slope Environmental Lapse Rate (SELR) of temperature along the Himalayan mountain slopes. This interplay forces seasonal variations and elevation dependent variability in temperature as well.

Overall this volume will provide comprehension from past to present over the Himalayas and associated changes and impacts.

\section{AUTHOR CONTRIBUTIONS}

$\mathrm{AD}$ and SA has conceptualized this special volume and worked toward it. Both authors contributed to the article and approved the submitted version.

Conflict of Interest: The authors declare that the research was conducted in the absence of any commercial or financial relationships that could be construed as a potential conflict of interest.

Copyright (c) 2020 Dimri and Allen. This is an open-access article distributed under the terms of the Creative Commons Attribution License (CC BY). The use, distribution or reproduction in other forums is permitted, provided the original author(s) and the copyright owner(s) are credited and that the original publication in this journal is cited, in accordance with accepted academic practice. No use, distribution or reproduction is permitted which does not comply with these terms. 